\title{
Simultaneously Determining Young's Modulus, Coefficient of Thermal Expansion, Poisson Ratio and Thickness of Thin Films on Silicon Wafer
}

\author{
Enboa Wu ${ }^{1}$, Albert J.D. Yang ${ }^{2}$ and Ching-An Shao ${ }^{3}$ \\ 1,2 Institute of Applied Mechanics, National Taiwan University \\ Taipei 106 Taiwan ROC, 1 ebwu@iam.ntu.edu.tw \\ ${ }^{3}$ Department of Electronic Materials, Chinmin College \\ Miaoli 351 Taiwan ROC
}

\begin{abstract}
Alustract
A method is demonstrated to simultaneously determine Young's modulus $(E)$, coefficient of thermal expansion $(\alpha)$, Poisson ratio $(v)$, and thickness $(t)$ of thin films on a silicon wa.fer. A digital phase-shifted reflection moiré (DPRM) technique was adopted to record the warpage slope of the film/wafer composites under temperature change. These data were used to compare with the ANSYS analysis, and the genetic algorithm (GA) was employed to search for the optimal mechanical parameters of the films. In the first experiment, 1.20-um thick copper was sputtered on a 4 -inch silicon wafer. The determined $E, \alpha, v$, and $t$ of this film were $95.9 \mathrm{Gpa}, 38.7 \mathrm{ppm} /{ }^{\circ} \mathrm{C}, 0.16$, and $1.13 \mathrm{um}$, respectively. The properties in the bulk state were found to be $E=110$ to 126 $\mathrm{GF}$, $\alpha=16.6$ to $17.6 \mathrm{ppm} /{ }^{\circ} \mathrm{C}$, and $v=0.33$ to 0.36 While the determined film thickness was in good agreement with the measured value, the deviation in $E, \alpha$ and $v$ was significant. The micro-structural difference between the bulk material and the thin film, and oxidation on the film surface were considered to be the two major causes to this deviation. The thickness of the oxidative layer was determined to be $326 \mathrm{~nm}$ with $E=89.6 \mathrm{GPa}$ by considering the $\mathrm{Cu}$-film as a two-layered structure. In order to verify the determined mechanical parameters of this 1.2-um $\mathrm{Cu}$ film, additional 2.4-um $\mathrm{Cu}$ film was sputtered on the $\mathrm{Cu} / \mathrm{Si}$ wafer and the determined mechanical parameters of this additional $\mathrm{Cu}$ film were identical to the data obtained in the 1.2-um film, which dernonstrated the validity of the developed method.
\end{abstract}

\section{Introduction}

Measurement of mechanical parameters of a thin film has been an important but difficult problem as the film deposited on a substrate is on the order or less than one micrometer. It is known that these properties might depend on the deposition process, thickness, and the exposed environment. In early days, the uniaxial tensile test was performed to directly meisure the Young's modulus [1]. This method is subjected to uncertainties, such as creep, and the difficulties to apply the loal and to measure the elongation, etc. X-ray diffraction is another tool to record the Young's modulus and Poisson ratio of thin films [2], but the difficulty also arises from the determination of the undeformed configuration of the thin film. Other methods, such as the method using the nanoindenter instrument, are also popular [3]. However, this is a destructive method and always induces plastic deformation.

Another method is to apply thermal or mechanical loads on a thin film deposited directly on a substrate, measure the deformation of the film/substrate composite, and extract the mechanical properties [4-6]. The measurement tool can be strain gauges, or full-field optical methods. The equations that govern the deformation of the film/substrate need to be developed. In the previously published works, Stoney equation [7] was usually employed. However, because the Young's modulus and the Poisson ratio are coupled in this equation, additional measurement tools or use of different substrates are needed to separate these two constants. It introduces complexity for experiment and uncertainty to the determined data.

In this study, we adopted a digital phase-shifted reflection moire (DPRM) method [8] to measure the slope change of multi-layered films sputtered on a 4-inch wafer. Reflection moire was used because both the film and the wafer were mirror-like. Introducing the phase shift method was to enhance the spatial resolution to $10^{-6} \mathrm{rad} / \mathrm{pixel}$. Finite element analyses using ANSYS were then performed, and the genetic search algorithm was adopted to obtain the optimal mechanical parameters using an objective function. Four mechanical parameters, i.e., Young's modulus, Poisson ratio, CTE, and film thickness, for these films were then determined.

\section{Experimental Procedure}

To start with the method, the deformation of a wafer with films deposited on its one side has to be measured when it is subjected to external loading. In this study, thermal loading was applied when the wafer was cooled from an elevated temperature. Once the wafer was deformed, the digital phaseshifted reflection moiré (DPRM) method was employed to measure the slope of the mirror-like composite structure. Use of DPRM aimed to enhance the measurement resolution to the order of $10^{-6} \mathrm{rad} / \mathrm{pixel}$ by adopting the phase shift algorithms. The schematic of the experimental set up is shown in Figure 1. When a parallel white light passed through the grating and the beam splitter, it hit the wafer surface to be measured. As the light reflected from the object, it reached the beam splitter, reflected again and was recorded by the CCD. Crossed grating was employed in order to measure the slope change on a two-dimensional manner.

In this study, we used a five-stepped phase shift algorithm. In each step, the shift was $\pi / 2$. Each fringe was obtained by nonlinear interpolation. In order to reconstruct the phase map after the filtering process, the fast Fourier transform (FFT) method was used. To filter out the high frequency noise and the DC background, the band-passed filter is set to be $11 \%$ 
larger than two times the signal frequencies in FFT analysis: A detailed description of the filtering process can also be found in [8].

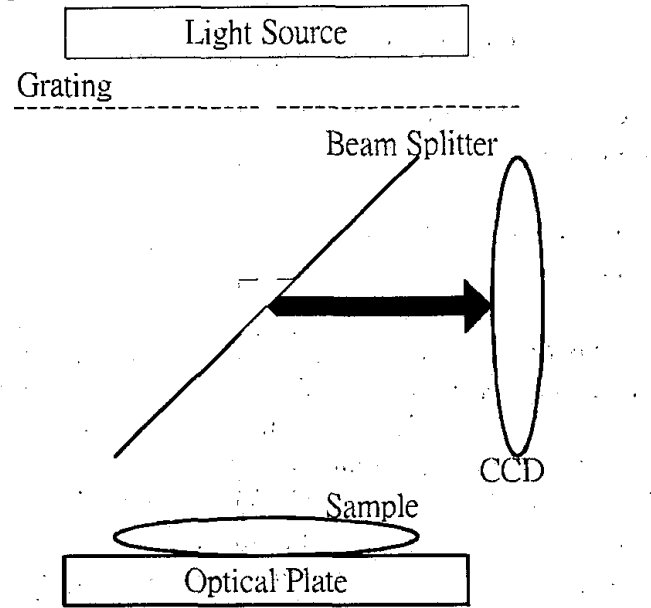

Figure 1 Schematic for the digital reflection moiré method

\section{Analysis Method}

In the finite element analysis, ANSYS was adopted to calculate the deformation of the film/wafer composite structure under thermal loading. Since the film on the wafer was of the micrometer order and a typical 4-inch wafer was 395 um thick, a composite element, Shell99 in ANSYS, was selected. This Shell99 element was proposed by Yunus and Kohnke [9]. In this element, the composite theory was adopted to take the stiffness change in the thickness direction into consideration. Thus, it is an ideal element for thin film analysis such as the case we encountered here. It has been proved that use of Shel199 and Solid73 elements in ANSYS gave essentially the same result [8]. On the other hand, the number of element used in Shell99 was several times smaller than in the case using Solid73, thus it avoided the excessive aspect ratio issues for elements used to model the thin film and saved tremendous computation time.

In each case, we started with a few sets of randomly generated mechanical parameters. ANSYS was employed to calculate the wafer warpage slope under the known temperature change. The stiffness matrix of the film/wafer composite structure was generated using these guessed mechanical parameters. The following quadratic objective function was used to find the degree of deviation between the guessed and measured warpage slopes:

$$
f i t=-\sum_{i=1}^{N}\left[\left(\phi_{x i}^{c a l}-\phi_{x i}^{\text {exp }}\right)^{2}+\left(\phi_{y i}^{c a l}-\phi_{y i}^{\exp }\right)^{2}\right]
$$

where $\phi_{x i}^{c a l}$ and $\phi_{y i}^{c a l}$ are the calculated slope values in each iteration using the guessed mechanical parameters, $\phi_{x i}^{\exp }$ and $\phi_{y i}^{\exp }$ are the measured slope distributions, and $\mathrm{N}$ is the number of the measured data. The ultimate goal was to reduce the value of the objective function to its minimal value. For this purpose the genetic algorithm (GA) was adopted as the searching tool. Four mechanical constants, i.e., Young's modulus, coefficient of thermal expansion,
Poisson ratio, and the thickness of the film were then regenerated by GA and the loop repeated until a convergence criterion was satisfied. Use of the generic algorithm also assured convergence of the data to a globally minimal value, which was the critical part of this study as there were many local minimal spots in this four-dimensional domain. A detailed description of the solution schemes for the inverse problem can be referred to $[10,11]$

Verification of this analysis method was performed using a composite plate-like structure loaded by a concentrated force at its center. The composite structure was composed of a mirror glued in the central portion of an aluminum plate using epoxy. The mirror was $141.32 \mathrm{~mm}$ in length, $49.35 \mathrm{~mm}$ in width, and $1.90 \mathrm{~mm}$ in thickness. The square aluminum plate was $142.38 \mathrm{~mm}$ wide and $1.01 \mathrm{~mm}$ thick. The plate was simply supported and the load of $2.01 \mathrm{~kg}$ was then applied. The developed DPRM was employed to measure the slope of the plate relative to its original configuration. ANSYS 8-node solid element (Solid73) was used to construct a finite element quarter-model and performed the forward analysis.

The ultrasonic method was used to measure the Young's modulus and Poisson ratio of the glass and the aluminum. These Young's modulus and Poisson ratio for of the glass and the aluminum are $70.64 \mathrm{GPa}$ and .20 and $71.4 \mathrm{GPa}$ and .34 , respectively. In this example, the Young's modulus and the Poisson ratio for the glass were assumed to be unknowns. The method described above was employed to search for these two properties using the measured slope data and the objective function in Eq. (1). The deviation between the measured data and the determined values were within $2 \%$. From this verification case, the analysis method was considered to be accurate. A more detailed description of the verification method can be found in [12].

\section{Study of Temperature Uniformity in Wafer}

The schematic of the experimental setup to measure the slope of a film/wafer composite is illustrated in Figure 2 . In order to avoid the turbulence inside the oven that caused drift of the moiré fringe, the measurement was performed outside the oven. One thermal couple mounted underneath the wafer was used to record the oven temperature when the wafer was heated. Once the temperature reached a preset value, the wafer was taken out of the oven and mounted on a three-post support, in which the tip of each post was attached with a thermal couple to measure the temperature change. The reflection moiré apparatus was then used to measure the slope change of the wafer during its cooling process.

Finite element analysis using ANSYS Plane77 element was performed to check whether there existed any thermal gradient within the wafer during the cooling process. The oven was heated to $156^{\circ} \mathrm{C}$. When the wafer was taken out and mounted on the three posts, the temperature was recorded to be $137.1^{\circ} \mathrm{C}$ using the same thermal couple mounted on the wafer. 18 seconds after the wafer was mounted outside the oven, the temperature on the wafer was recorded to be 78.1 ${ }^{\circ} \mathrm{C}$. The input parameters for the finite element model were the thickness $(h)$, thermal conductivity $(k)$, specific heat $c$, and density. For silicon wafer, these data were $655.5 \mathrm{um}, 138.5$ $\mathrm{W} / \mathrm{mK}, 729 \mathrm{~J} / \mathrm{KgK}$, and $2340 \mathrm{~kg} / \mathrm{m}^{3}$. For the copper film used 
in this run, these data were $4.5 \mathrm{um}, 397.0 \mathrm{~W} / \mathrm{mK}, 386 . \mathrm{J} / \mathrm{KgK}$, and $8960 . \mathrm{Kg} / \mathrm{m}^{3}$, respectively. The finite element analysis result is shown in Figure 3. It is found that the thermal gradient along the thickness direction of the wafer became negligible 18 seconds after the wafer was taken out of the oven. As a result, in the subsequent experiment the warpage slope was always measured at least 18 seconds after the wafer was taken out of the oven to avoid any temperature gradient effect



Figure 2 Schematic of the experimental setup for slope measurement of a wafer using the developed DPRM method

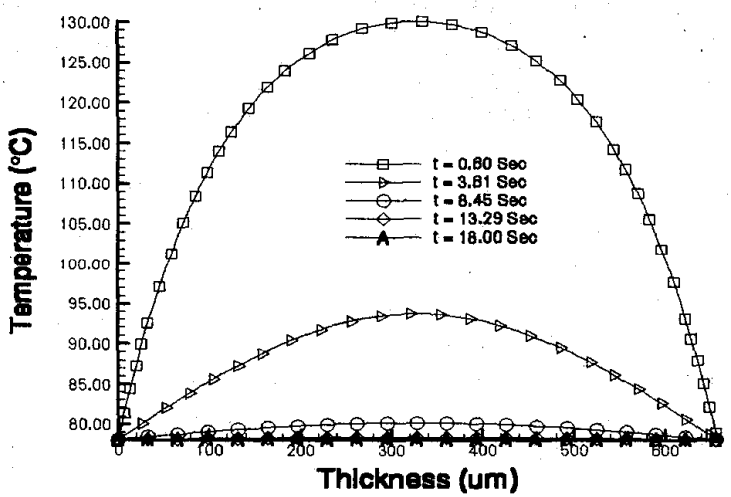

Figure 3 Temperature gradient predicted by ANSYS across the wafer thickness

\section{Results and Discussion}

\section{Results of One-Layered Sputtered Cu Film}

In the first step experiment, a one-layered $\mathrm{Cu}$ film $1.2 \mathrm{um}$ thick was sputtered on a 4 -inch silicon wafer 395.0 um thick. Thickness of the film was measured using a surface profile meter. The variation of the film thickness was recorded to be within $5 \%$. The sputtering parameters were 250 standard $\mathrm{cm}^{3} / \mathrm{min}$ Ar flow with $5 \mathrm{~kW}$ power. The wafer thickness, before sputtering, was measured using a micrometer. No further backside lapping was performed to avoid any adverse influence on the measurement.

The $\mathrm{Cu} / \mathrm{Si}$ wafer was then heated inside the oven. When the temperature reached $150^{\circ} \mathrm{C}$, this wafer was taken out of the oven and mounted carefully on the tri-post. The exprerimental setup has been illustrated in Figure 2. In this case, the grating pitch and the object-to-grating distance were $200 \mathrm{um}$ and $630 \mathrm{~mm}$, respectively. When the temperature cooled to $81.0^{\circ} \mathrm{C}$, the first DPRM picture was taken. It represented the initial state of the wafer slope. The second picture was taken when the temperature reached $20.8^{\circ} \mathrm{C}$. Additional four pictures were taken for phase shift purposes. The temperature difference was $60.2^{\circ} \mathrm{C}$. The slope of the wafer due to this temperature change was then obtained. For verification purposes, this slope change in the $x$ and $y$ directions, fitted by a polynomial, were calculated to be $2.62 \mathrm{E}-05$ and $2.78 \mathrm{E}-05$. The deviation is about $5 \%$, and is considered to be small. It shows that the materials made of silicon wafer and the sputtering $\mathrm{Cu}$ film was distributed isotropically.

The mechanical data used for the silicon wafer affect the corresponding film properties significantly. In this study, the Young's modulus, Poisson ratio and the coefficient of thermal expansion were obtained as $187.0 \mathrm{GPa}, .25$, and $2.5 \mathrm{ppm} /{ }^{\circ} \mathrm{C}$, respectively [13]. To verify the Young's modulus of the silicon, a three-point bending test was performed. The 4-inch wafer was cut into beams. A strain gauge was mounted at the center of each beam on the same side of the two supports. By measuring the strain data and using the Euler beam theory, the Young's modulus of $187 \pm 1 \mathrm{GPa}$ was obtained from the threepoint bending tests. The experiment was done for beams cut at two perpendicular directions of the wafer to check its isotropy, and essentially identical Young's modulus data were obtained.

The finite element model for the slope calculation was constructed by the 8-node 250-layer structural shell element (Shell99). GA was employed as the search tool for the optimal mechanical parameters of the sputtered $\mathrm{Cu}$ film. The objective function used is the same as that in Eq. (1). The result is listed in Table 1 . The bulk material properties for pure copper are $E=110$ to $126 \mathrm{GPa}, \alpha=16.6$ to $17.6 \mathrm{ppm} /{ }^{\circ} \mathrm{C}$, $v=0.33$ to 0.36 . The thickness, $t$, of the $\mathrm{Cu}$ film sputtered on the wafer was $1.20 \mathrm{um}$. On the other hand, the determined results for the $\mathrm{Cu}$ film were $E=95.9 \mathrm{GPa}, \alpha=38.7 \mathrm{ppm} /{ }^{\circ} \mathrm{C}$, $v=0.16$, and $t=1.13 \mathrm{um}$. It can be found that the deviation in the film thickness was $6 \%$, which is close to the sputtered film thickness variation of $5 \%$. However, the deviation between the bulk and the film properties were $15 \%$ to $32 \%$ and $55 \%$ to $57 \%$ for Young's modulus and coefficient of thermal expansion, respectively. The deviation was higher than $100 \%$ for the Poisson ratio.

A second run was performed by taking the film thickness of $1.20 \mathrm{um}$ as a known value and only searched for the Young's modulus, Coefficient of thermal expansion, and Poisson's ratio. The data were $E=96.5 \mathrm{GPa}, \alpha=38.8 \mathrm{ppm} /$ ${ }^{\circ} \mathrm{C}$, and $v=0.19$. The deviation between these two searches is considered to be negligible comparing to their deviation to the bulk material properties.

The difference in mechanical properties for $\mathrm{Cu}$ in the film and the bulk states might be partly attributed to the formation of the $\mathrm{CuO}$ layer. When this oxidative layer was formed, the originally shining $\mathrm{Cu}$ surface becomes darker. In this study, the $\mathrm{Cu} / \mathrm{Si}$ wafer was subjected to temperature up to $150^{\circ} \mathrm{C}$ in the oven before it was taken out for measurement. Thus, $\mathrm{CuO}$ layer formed. This thin layer has loose microstructure. As a result, it inevitably affected the mechanical properties of the deposited film if we treated the film as one structure. A detailed analysis will be shown in the section below. 
On the other hand, increase of the coefficient of thermal expansion for the $\mathrm{Cu}$ film might be due to the near twodimensional thin film structure, as compared to the 3D structure in its bulk state, so that the lateral resistance became smaller when temperature of the film changed. It thus increased the value of the coefficient of thermal expansion. This interesting phenomenon was observed in other metals, such as $\mathrm{Al}, \mathrm{Ag}, \mathrm{Fe}, \mathrm{Ni}-\mathrm{P}$ alloy, and even $\mathrm{Si}$ and $\mathrm{Ge}[6,12]$. Also, It was reported that the grain size for $\mathrm{Cu}$ increased as the film thickness increased [14]. As a result, it affected the Young's modulus, coefficient of thermal expansion, and Poisson ratio of the $\mathrm{Cu}$ film.

\begin{tabular}{|c|c|c|c|c|c|}
\hline & \multicolumn{4}{|c|}{ Material Properties } \\
\hline & & $\begin{array}{c}\mathrm{E} \\
(\mathrm{GPa})\end{array}$ & $v$ & $\mid \begin{array}{c}\mathrm{CTE} \\
(\mathrm{ppm} / \mathrm{C})\end{array}$ & $\begin{array}{c}\mathrm{h} \\
(\mathrm{um})\end{array}$ \\
\hline \multicolumn{2}{|c|}{$\mathrm{Cu}$ (Bulk). } & 126 & 0.34 & 17 & -- \\
\hline $\begin{array}{l}\text { Inversed } \\
\text { sp.Cu/Si }\end{array}$ & $\begin{array}{c}\mathrm{Cu} \\
\mathrm{h}=1.2 \mathrm{um}\end{array}$ & 96.5 & 0.19 & 38.8 & 1.13 \\
\hline $\begin{array}{c}\text { Inversed } \\
\mathrm{sp} . \mathrm{Cu} / \mathrm{Cu} / \mathrm{Si}\end{array}$ & $\begin{array}{c}\mathrm{Cu} \\
\mathrm{h}=2.4 \mathrm{um}\end{array}$ & 96.5 & 0.19 & 38.8 & 2.40 \\
\hline
\end{tabular}

Table 1 Comparison of the mechanical parameters of bulk $\mathrm{Cu}, 1.2-\mathrm{um}$ thick $\mathrm{Cu}$ film and 2.4-um $\mathrm{Cu}$ film

\section{Results of Two-Layered Cu Films}

In order to verify the developed method, a second experiment was designed by sputtering additional layer of $\mathrm{Cu}$ film on the previous wafer. The thickness of this additional film was $2.40 \mathrm{um}$. Then, the warpage slope of this $\mathrm{Cu} / \mathrm{Cu} / \mathrm{Si}$ composite structure was measured during the cooling stage. This time, the mechanical properties of the first-layered $\mathrm{Cu}$ film of $1.2 \mathrm{um}$ thick were set to be the values determined previously, i.e., the data shown on the fourth row of Table 1, Then, the same method was applied to search for the four mechanical parameters of the second-layered $\mathrm{Cu}$ film. In this case, the film thickness was found to obe identical to the measured values, i.e., 2.4 um. Further, the three mechanical properties, $E, \alpha$, and $v$, were surprisingly found to be identical to the values for the first-layered $\mathrm{Cu}$ film. This is considered to be reasonable as, in principle, the mechanical properties of these two layers of $\mathrm{Cu}$ film should be identical

As mentioned earlier, it is well known that $\mathrm{CuO}$ always forms when it exposes to the air. In this study, we attempted to determine the mechanical parameters of this thin $\mathrm{CuO}$ layer. By doing this we used the same measured slope data and treated the structure as a $\mathrm{CuO} / \mathrm{Cu} / \mathrm{Si}$ composite. We still limited the number of the searched parameters to four. Thus, the $E, \alpha$, and $v$ values of the $\mathrm{Cu}$ film were assumed to be the same as the properties in the bulk state, and the thickness of $t=1.13 \mathrm{um}$ was used. These data were listed as the last row of Table 2 and were put in " $\{$.$\} " to represent the known values.$ Then the mechanical parameters of the $\mathrm{CuO}$ film were searched. The results were $E=89.6 \mathrm{GPa}, \alpha=40.7 \mathrm{ppm} /{ }^{\circ} \mathrm{C}, \mathrm{v}=$ 0.39 , and $t=326 \mathrm{~nm}$. The determined Young's modulus is considered to be reasonable as it is smaller than its counterpart in the bulk state.

\begin{tabular}{|c|c|c|c|c|c|}
\hline \multicolumn{2}{|c|}{} & $\begin{array}{c}\mathrm{E} \\
(\mathrm{GPa})\end{array}$ & $\nu$ & $\begin{array}{c}\mathrm{CTE} \\
(\mathrm{ppm} / \mathrm{C})\end{array}$ & $\begin{array}{c}\mathrm{h} \\
(\mathrm{um})\end{array}$ \\
\hline \multicolumn{2}{|c|}{$\mathrm{Cu}(\mathrm{Bulk})$} & 126 & 0.34 & 17 & -- \\
\hline \multirow{2}{*}{$\begin{array}{c}\text { Inversed } \\
\mathrm{CuO} / \mathrm{Cu} / \mathrm{Si}\end{array}$} & $\mathrm{CuO}$ & 89.6 & 0.39 & 40.7 & 326 \\
\cline { 2 - 6 } & $\mathrm{Cu}$ & $\{126\}$ & $\{0.34\}$ & $\{17\}$ & $\{1.13\}$ \\
\hline
\end{tabular}

Table 2 Determined mechanical parameters for $\mathrm{CuO}$ layer grown on the surface of the sputtered $\mathrm{Cu}$ film

\section{Conclusion}

We have reported a method to determine Young's modulus, coefficient of thermal expansion, Poisson ratio, and thickness of $\mathrm{Cu}$ films deposited on a 4-inch wafer. In this method, we adopted a digital phase-shifted reflection moiré (DPRM) technique to measure the warpage slope of the mirror-like $\mathrm{Cu} / \mathrm{Si}$ composite structure. The resolution was up to $10^{-6} \mathrm{rad} / \mathrm{pixel}$ when the phase shift method was employed. The slope measurement was performed when the $\mathrm{Cu} / \mathrm{Si}$ structure was cooled from approximately $150^{\circ} \mathrm{C}$. An inverse method has been developed to determine these mechanical parameters of the thin film. The convolution relationship between the mechanical parameters and the slope change of the wafer was constructed using ANSYS. The genetic algorithm (GA) was adopted as the searching tool for the optimal mechanical parameters of the thin film. While the determined film thickness had good agreement with the measured values, all the three other properties, Young's modulus, coefficient of thermal expansion, and Poisson ratio, were found to deviate significantly from the values in the bulk state. This deviation was attributed to the formation of $\mathrm{CuO}$ layer and the difference in microstructure. In order to verify this method, we sputtered an additional 2.4-um thick $\mathrm{Cu}$ film on this $\mathrm{Cu} / \mathrm{Si}$ composite. We then did the warpage measurement, and searched the optimal mechanical parameters. Identical mechanical parameters for these two films were obtained. On the other hand, we also determined the mechanical parameters of the $\mathrm{CuO}$ layer grown on the surface of the $\mathrm{Cu}$ film. The Young's modulus for this $\mathrm{CuO}$ layer was lower than the $\mathrm{Cu}$ Young's modulus in the bulk state, which is considered to be reasonable.

\section{Acknowledgments}

Wafer sputtering was done in the Electrical Research Service Organization (ERSO) of the Industrial Technology Research Institute (ITRI), Taiwan, ROC. This research was supported by the National Science Council, ROC, under Contract Number NSC91-2212-E-002-033.

\section{References}

1. Blakely, J. M., "Mechanical Properties of VacuumDeposited Gold Films," J. Appl. Phys., Vol. 35, pp. 1756, 1964.

2. Loopstra, O. B., van Snek, E. R., de Keijser, Th. H., and Mittemeijer, E. J., "Model for Stress and Volume Changes of a Thin Film on a Substrate upon Annealing: Application to Amorphous Mo/Si Multilayers," Physical Review B, Vol. 44, No. 24, pp. 13519-13533, 1991.

3. EI Khakani, M. A., Chaker, M., O'Hern, M.E., and Oliver, W. C., "Linear Dependence of Both the Hardness 
and the Elastic Modulus of Pulsed Laser Deposited a-SiC Films upon Their Si-C Bond Density," J. Appl. Phys., Vol. 82, No. 9, pp. 4310-4318, 1997.

4. Zhao, J. H., Ryan, T., Ho, P. S., McKerrow, A.J., and Shih, W.Y., "Measurement of Elastic Modulus, Poisson ratio, and Coefficient of Thermal Expansion of On-Wafer Submicron Films," Journal of Applied Physics, Vol. 85, No. 9, pp. 6421-6424, 1999.

5. Zhao, J. H., Du, Y., Morgen, M., and Ho, P. S, "Simultaneous Measurement of Young's modulus, Poisson ratio, and Coefficient of Thermal Expansion of Thin Films on Substrates," J. Appl. Phys., Vol. 87, No. 3, pp. 1575-1577, 2000.

6. de Lima, M. M., Lacerda, R. G., Vilcarromero, J., Marques, F. C., oefficient of Thermal Expansion and Elastic Modulus of Thin Films," Journal of Applied Physics, Vol. 86, No. 9, pp. 4936-4942, 1999.

7. Stoney, G. G., Proc. Roy. Soc. London, Vol. A82, pp. 172, 1909.

8. Yang, C.D., "Identification of Thin-Film Mechanical

'Properties by Inverse Methods," Ph D Dissertation, Institute of Applied Mechanics, National Taiwan University, Taipei, Taiwan, ROC, 2002.

9. Yunus, S. M., and Kohnke, P. C., "An Efficient ThroughThickness Integration Scheme in an Unlimited Layer Doubly Curved Isoparametric Composite Shell Element," International Journal for Numerical Methods in Engineering, Vol. 28, pp. 2777-2793, 1989.

10. Yen, C. S., and Wu, E., "On the Inverse Problems of Rectangular Plates Subjected to Elastic Impact, Part I: Method Development and Numerical Verification," ASME Journal of Applied Mechanics, Vol. 62, pp. 692698, 1995.

11. Yen, C. S., and Wu, E., "On the Inverse Problems of Rectangular Plates Subjected to Elastic Impact, Part II: Experimental Verification and Further Applications," ASME Journal of Applied Mechanics, Vol. 62, pp. 699$705,1995$.

12.. Wu, E., Yang, A. J. D., Shao, C. A., and Yen, C. S., "Determination of Mechanical Properties of Thin Film on Silicon Wafer," Proceedings of 2003 ASME International Mechanical Engineering Congress, Washington DC, USA.

13. Lau, J.H., Thermal Stress and Strain in Microelectronics Packaging, Van Nostrand Reinhold, 1993.

14. Lee, S.Y., Choi, S.H., and Park, C.O., "Oxidation, Grain Growth and Reflow Characteristics of Copper Thin Films Prepared by Chemical Vapor Deposition," Thin Solid Films, Vol 359, pp. 261-267, 2000. 